\section{BMJ Paediatrics Open}

\title{
Can social robots help children in healthcare contexts? A scoping review
}

\author{
Julia Dawe, ${ }^{1}$ Craig Sutherland, ${ }^{2}$ Alex Barco, ${ }^{3}$ Elizabeth Broadbent ${ }^{1}$
}

To cite: Dawe J, Sutherland C, Barco A, et al. Can social robots help children in healthcare contexts? A scoping review. BMJ Paediatrics Open 2018;0:e000371. doi:10.1136/ bmjpo-2018-000371

Received 14 September 2018 Revised 13 December 2018 Accepted 14 December 2018
Check for updates

(C) Author(s) (or their employer(s)) 2018. Re-use permitted under CC BY-NC. No commercial re-use. See rights and permissions. Published by BMJ

${ }^{1}$ Department of Psychological Medicine, Faculty of Medical and Health Sciences, The University of Auckland, Auckland, New Zealand

${ }^{2}$ Department of Electrical and Computer Engineering, Faculty of Engineering, The University of Auckland, Auckland, New Zealand

${ }^{3}$ Department of Communication Science, Faculty of Social and Behavioural Sciences, University of Amsterdam, Amsterdam, The Netherlands

Correspondence to Dr Elizabeth Broadbent; e. broadbent@auckland.ac.nz

\section{ABSTRACT}

Objective To review research on social robots to help children in healthcare contexts in order to describe the current state of the literature and explore future directions for research and practice.

Design Scoping review.

Data sources Engineering Village, IEEE Xplore, Medline, PsycINF0 and Scopus databases were searched up until 10 July 2017. Only publications written in English were considered. Identified publications were initially screened by title and abstract, and the full texts of remaining publications were then subsequently screened.

Eligibility criteria Publications were included if they were journal articles, conference proceedings or conference proceedings published as monographs that described the conceptualisation, development, testing or evaluation of social robots for use with children with any mental or physical health condition or disability. Publications on autism exclusively, robots for use with children without identified health conditions, physically assistive or mechanical robots, non-physical hardware robots and surgical robots were excluded.

Results Seventy-three publications were included in the review, of which 50 included user studies with a range of samples. Most were feasibility studies with small sample sizes, suggesting that the robots were generally accepted. At least 26 different robots were used, with many of these still in development. The most commonly used robot was NAO. The evidence quality was low, with only one randomised controlled trial and a limited number of experimental designs.

Conclusions Social robots hold significant promise and potential to help children in healthcare contexts, but higher quality research is required with experimental designs and larger sample sizes.

\section{INTRODUCTION}

Social robots are increasingly being developed, tested and used in healthcare contexts. ${ }^{1-3}$ Although in relative infancy, social robotic technology holds the potential to assist the healthcare system, helping to meet high healthcare demands and to enhance and support care. ${ }^{34}$ Children present unique care needs and social robots may provide a useful platform through which these needs can be met. ${ }^{15}$ Illness can remove children from their normal social networks and pose challenges for coping with treatment and lifestyle changes. Robots could assist children
What is already known on this topic?

Many research teams are building robots to help care for the growing ageing population.

- Preliminary studies provide evidence that robots can provide companionship for older people.

Robots may also be suitable for children in hospital.

\section{What this study hopes to add?}

This review shows that research into companion robots for children in health contexts is increasing.

Robots are being developed especially for children with disabilities and impairments, hospitalised children and those with chronic health conditions.

- Preliminary feasibility studies are promising but higher quality trials are needed.

managing chronic illness through education and encouragement to perform healthy behaviours, help distract children coping with acute medical procedures or provide companionship and comfort. In recent years, there has been considerable interest in the application of social robots to the care of the elderly (eg, see Bemelmans et al, Mordoch et al and Robinson et $a l^{6-8}$ ), and recently a scoping review was published in this area. ${ }^{9}$ However, research into the application of social robots to help children in healthcare contexts is at an emergent stage ${ }^{110}$ and has not yet been reviewed.

This scoping review was thus conducted to investigate how social robots have been used to help children in healthcare contexts, in order to clarify and summarise the current state of the literature and to contribute to the facilitation of ongoing research and potential clinical applications. Specifically, the review aims to determine the types of studies that have been conducted, the health conditions that social robots are used with or intended for use with, the types of robots used, the purposes the robots serve, the effectiveness of the robots, how the area of research has developed over time and the gaps that remain in the research. This is a high-level review 
summarising the field, and it includes a broad range of study designs. It is not a systematic review and does not focus on a narrow range of quality-assessed studies.

\section{METHODS}

A scoping review was conducted that investigated the use of social robots for children in healthcare applications. The research question was 'Can social robots help children in healthcare contexts?'. Guidelines were consulted on conducting systematic scoping reviews. ${ }^{11}$ We used an electronic search strategy of relevant databases, but reference lists were not searched. Ethical approval was not required.

\section{Search strategy}

Publications were identified through searching the electronic databases of Engineering Village, IEEE Xplore, Medline, PsycINFO and Scopus. The search was limited to publications published in English, published until 10 July 2017. The following search strategy was used in Scopus, and this search pattern was adapted to suit the requirements of each database: ((robot*) AND (hospital* OR health* OR clinic* OR treatment* OR therap* OR patient* OR outpatient* OR rehab*) AND (child* OR pediatric* OR paediatric* OR adolesc* OR teen*) AND NOT (surg*)). Relevant subject headings were selected in each database in addition to the use of keywords, and an age limit of $0-18$ years was applied.

\section{Screening}

After duplicate records were removed, two authors independently screened the titles, abstracts and keywords against the eligibility criteria. Full texts for the remaining publications were obtained and screened by the same two authors. Any differences were resolved through consultation with a third author.

\section{Eligibility}

Publications were included if they were journal articles, conference proceedings or conference proceedings published as monographs, before 10 July 2017, written in English. Book chapters, monographs that were not published conference proceedings and reviews were excluded. Included publications described the conceptualisation, development, testing or evaluation of social robots for children (aged 0-18 years) with any kind of mental or physical health condition or disability. Publications focusing exclusively on autism were excluded as this has been reviewed previously ${ }^{12}{ }^{13}$; however, publications focusing on the broader classification of neurodevelopmental disorders were included. Publications on preventative health behaviours in children without identified health conditions were excluded, as were publications concerning social robots in the context of normative child development. A social robot was conceptualised as a physical electromechanical entity capable of or perceived as capable of sensing and moving, as well as forming a friendly companionship with humans. Purely physically-assistive mechanical robots and surgical robots were excluded, as well as virtual reality. Publications were not excluded on the basis of methodological quality due to the emergent nature of the field.

\section{Data extraction and synthesis}

Data were extracted by two authors (JD and $\mathrm{AB}$ ) using a predetermined spreadsheet. Variables extracted were study type, country, whether a user study was conducted, study setting, outcomes considered, findings, target population, sample, number and age of participants, type of robot, control of robot and purpose of the robot. Unlike a systematic review, a scoping review does not aim to synthesise evidence but to present a narrative account, and the results are described in sections aligning with the aims.

\section{Patient and public involvement statement}

Patients and public were not involved in this review.

\section{RESULTS}

\section{Study selection}

The initial search produced a total of 4179 results. Once duplicates were removed, 1961 publications remained. Initial screening of the titles and abstracts resulted in a working pool of 520 publications. Titles and abstracts were thoroughly screened according to the full eligibility criteria, resulting in 83 publications for which full texts were obtained. Screening full texts resulted in a final 73 publications (see figure 1 and table 1 ). Of the 73 publications included, 53 were conference proceedings, six were conference proceedings published as monographs and 14 were journal articles.

\section{Types of studies conducted}

Publications consisted of technical development papers alone $(n=17)$, technical development papers with a user study (mostly feasibility studies) $(\mathrm{n}=17)$, feasibility studies alone $(n=13)$, experimental designs $(n=11)$, discussion papers $(n=4)$, discussion papers with user study $(n=3)$, single-subject designs $(\mathrm{n}=2)$, randomised control trials (RCTs) ( $\mathrm{n}=1)$, case-studies $(\mathrm{n}=2)$, interview/focus group studies $(n=1)$ and study proposals $(n=2)$ (see table 1 ).

\section{Countries}

Twenty-three countries were included (see table 1 and figure 2). Most publications came out of Italy, the Netherlands, or Spain, and some publications included more than one of these countries. This may reflect greater funding or interest in this area of research in these countries compared with elsewhere.

\section{User studies}

The majority of publications included a user study $(\mathrm{n}=50)$ (table 2), four proposed a user study and four consulted users. 


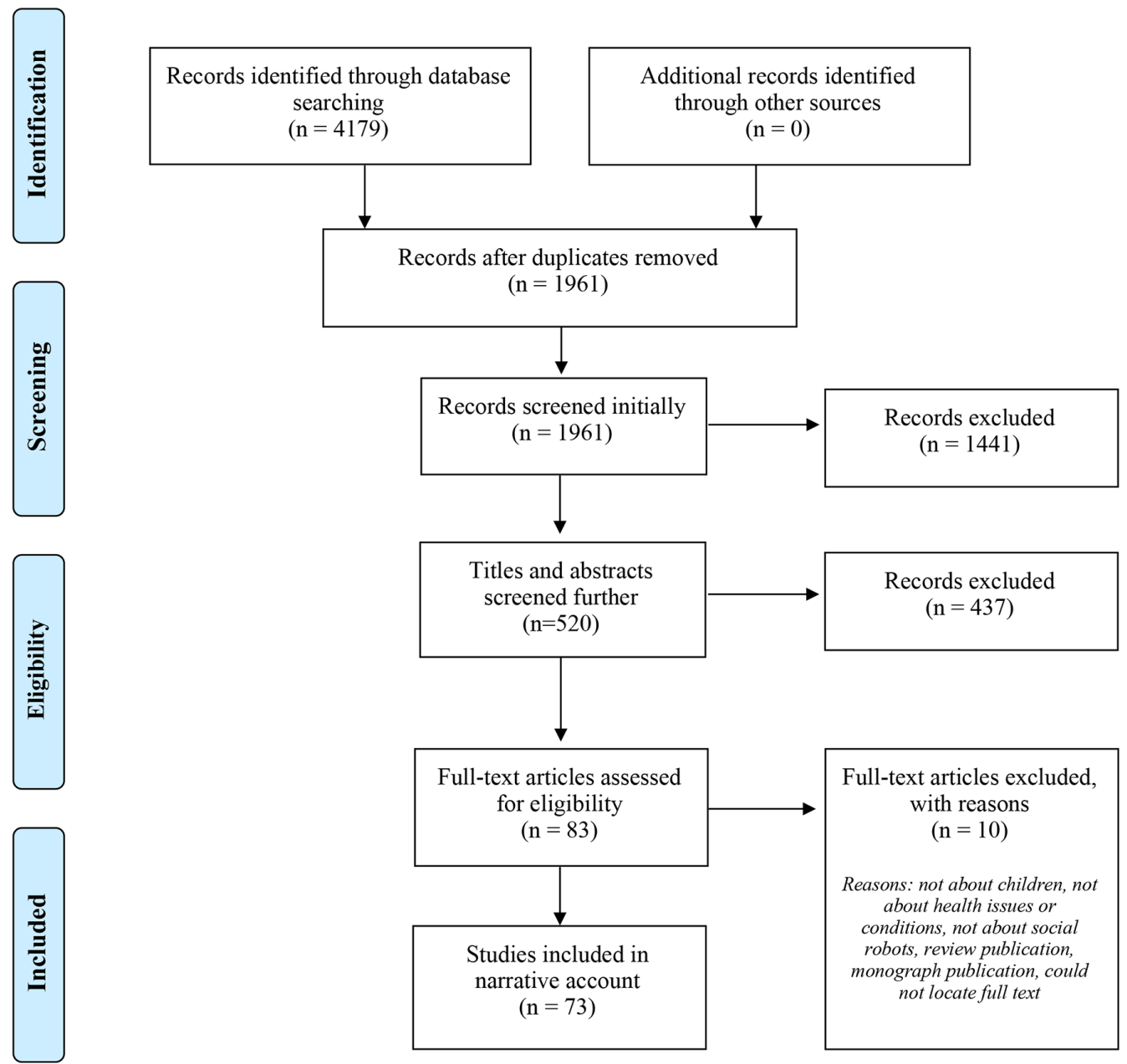

Figure 1 Preferred Reporting Items for Systematic Reviews and Meta-Analyses 2009 flow diagram.

\section{Health conditions social robots are used with}

Target populations

Disabilities and impairments comprised the largest grouping $(n=27)$ (see table 1). Cerebral palsy featured in nine of these publications, with other identified groups including cognitive, physical and neurodevelopmental disabilities, traumatic brain injury and communication impairments.

Other common target populations were hospitalised children $(n=18)$, diabetes $(n=15)$, cancer $(n=3)$, children attending medical appointments $(\mathrm{n}=3)$ and children unable to attend school $(n=2)$. Less common target populations featuring only once included anxiety, myalgic encephalomyelitis, disruptive behaviour problems, users in socially difficult environments and obesity.

\section{Samples}

There was considerable overlap between target populations and the samples employed, although children without identified health conditions were sometimes sampled despite not being the target end-users $(n=5)$. In some cases, the sample was described only as "children' $(n=2)$. The age range varied from 1 to 18 years. The number of participants ranged from 2 to 70 (see figure 3 ). The majority reported small sample sizes (see table 2).

\section{Setting}

Hospitals $(n=11)$, rehabilitation clinics/centres $(n=10)$ and schools $(\mathrm{n}=7)$ were the most common settings. Robots that served a telepresence purpose were used across hospitals, homes and schools $(\mathrm{n}=3)$. Additional settings included medical centres $(n=2)$, laboratories $(\mathrm{n}=3)$, diabetes summer camps $(\mathrm{n}=2)$, a clinical training centre $(n=1)$, an institute for cerebral palsy $(n=1)$, a dental clinic $(n=1)$, inpatient and outpatient clinics $(n=2)$ and event days at a university and museum $(n=2)$. In some cases, multiple settings were utilised $(n=2)$ or the setting was not specified $(n=4)$.

\section{Types of robots used}

Twenty-six different robots were used (see table 1), ranging in stage of development from concept formulation through to commercially available models. The humanoid NAO robot was the most common $(n=29)$. IROMEC robot was the second most common robot $(n=8)$, used exclusively with children with disabilities and impairments. Some other robots identified were Pleo, 


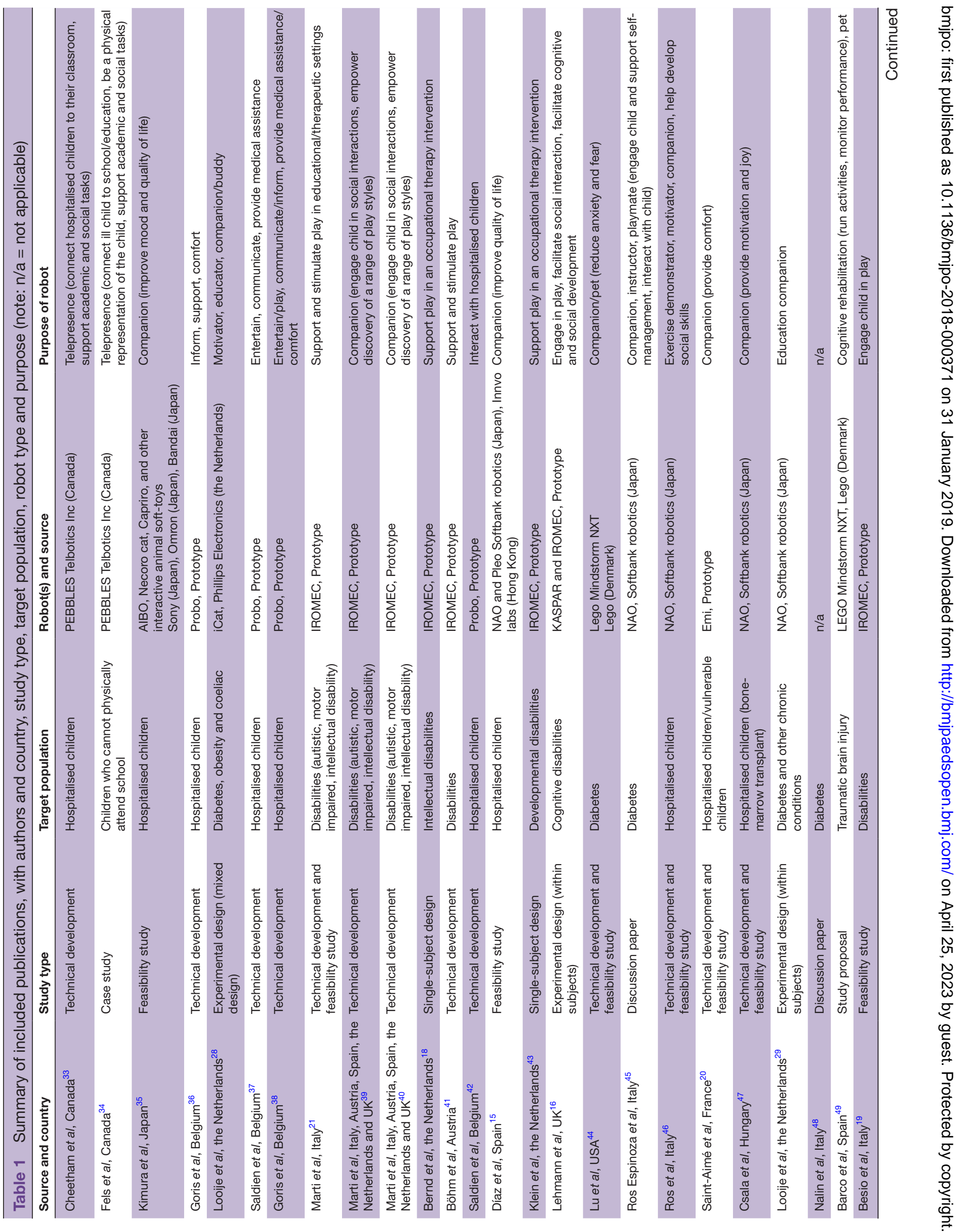



IIIIIIIIIIIIIII

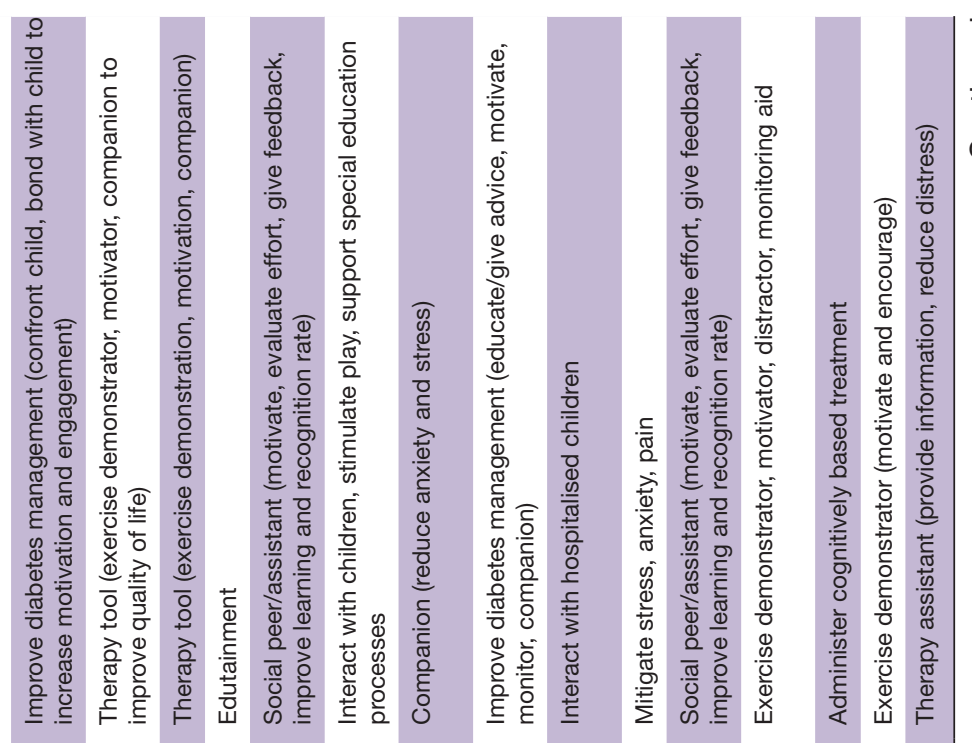

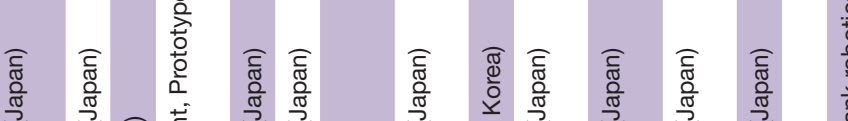

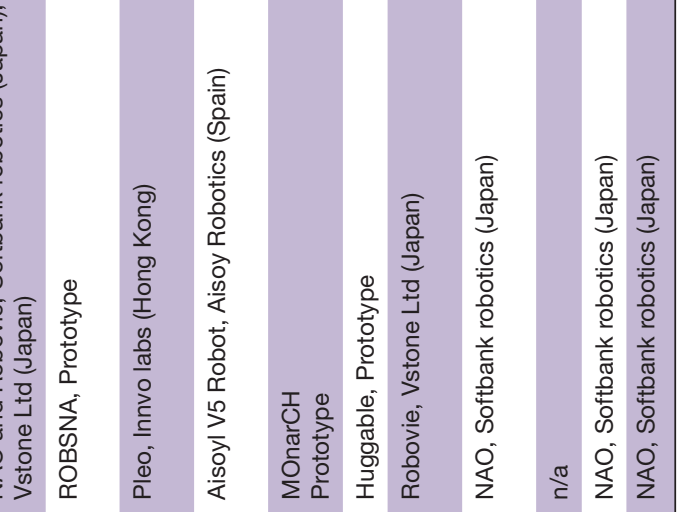

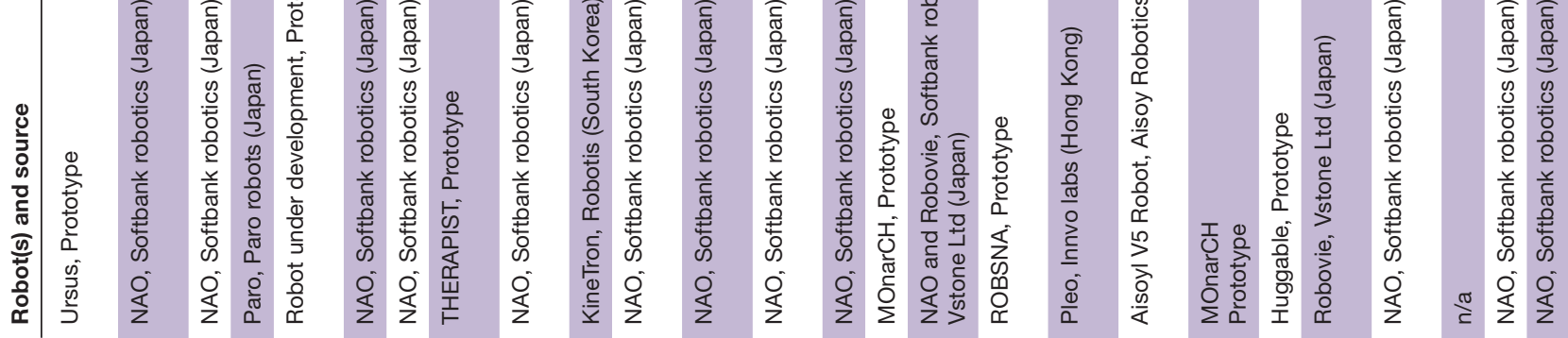

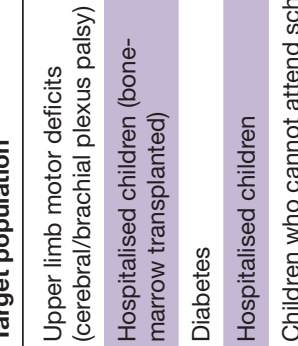

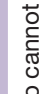

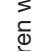

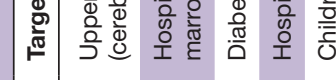

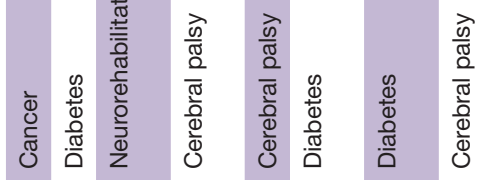

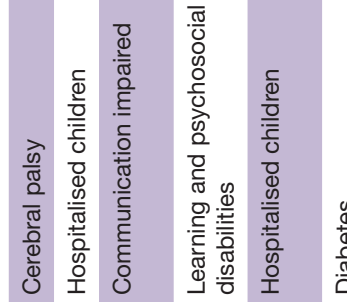

$\frac{0}{0}$

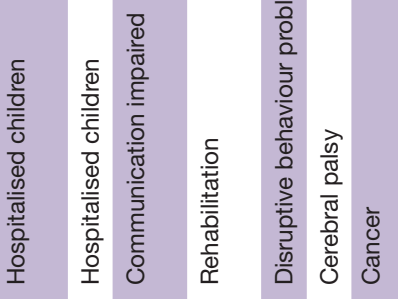

동

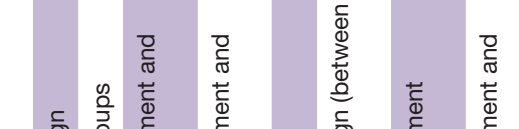

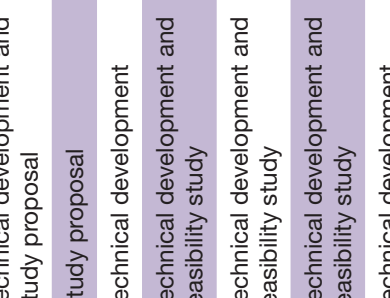

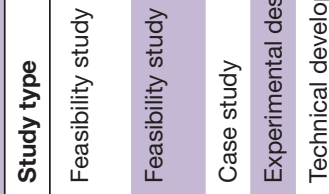

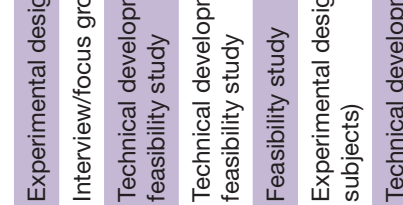

응

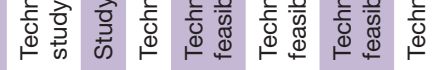

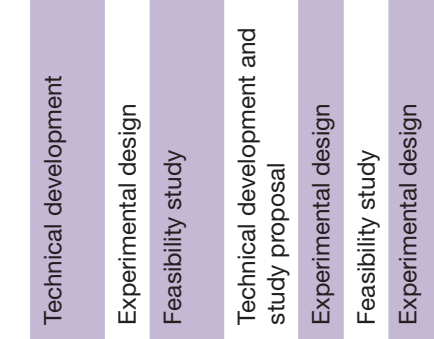

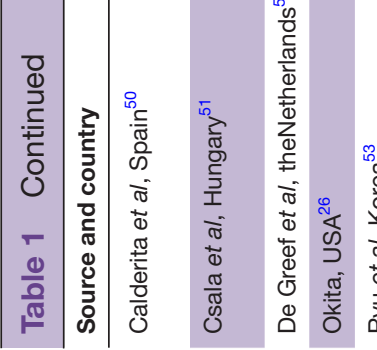

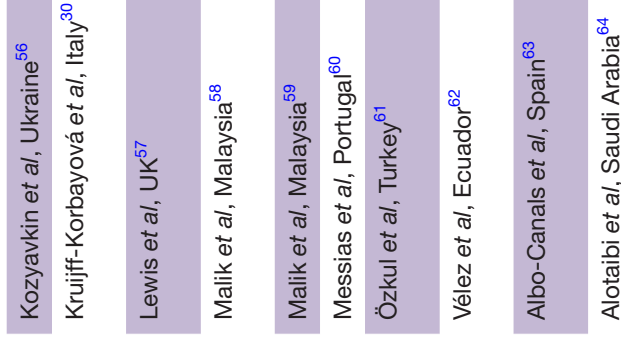

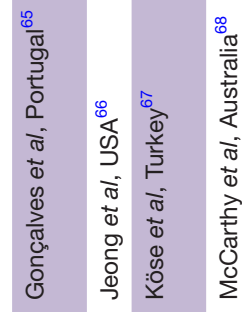

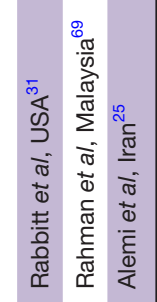

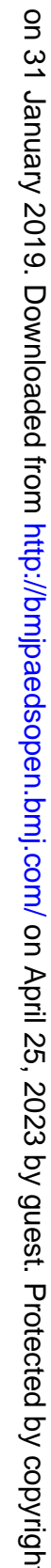




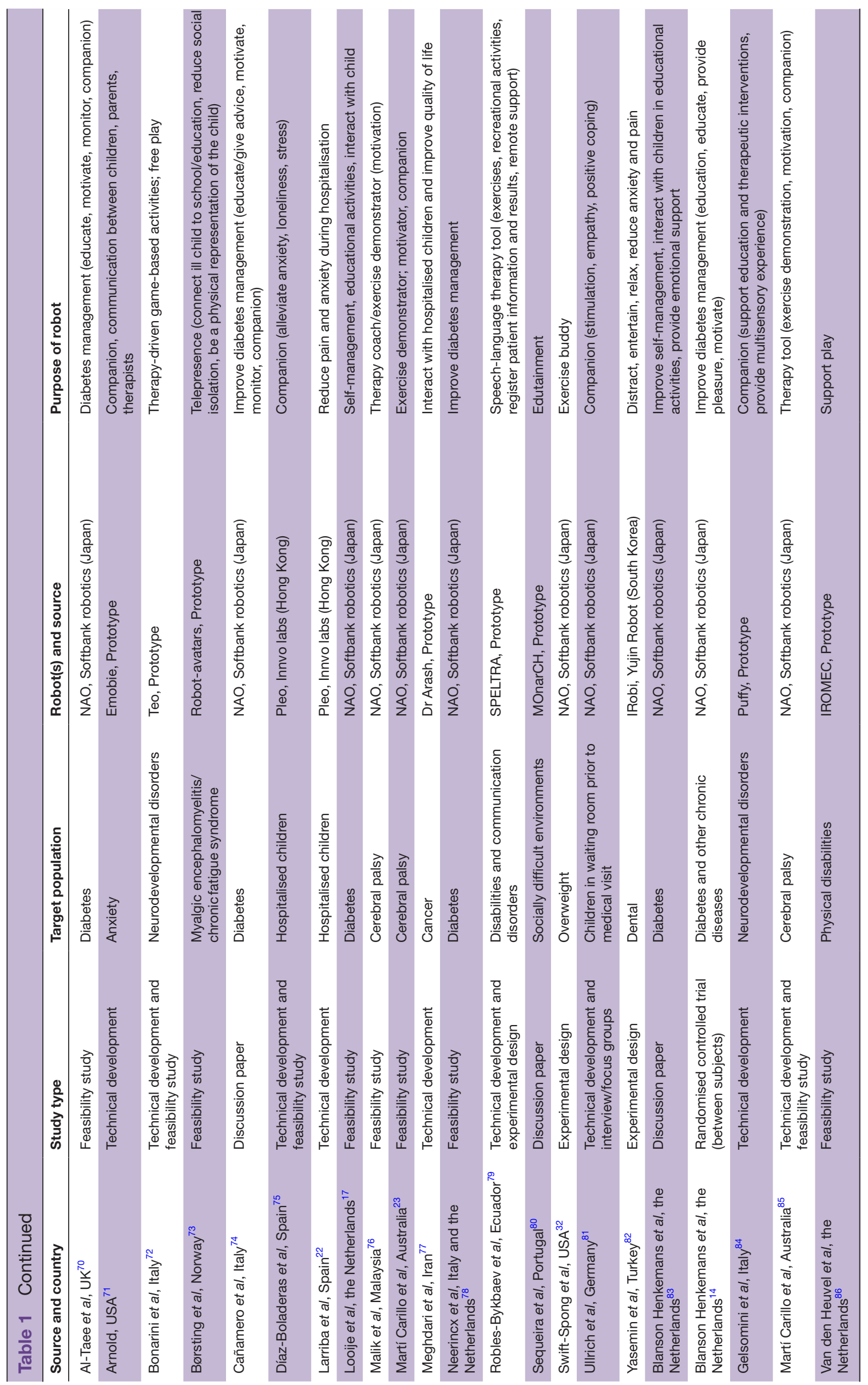




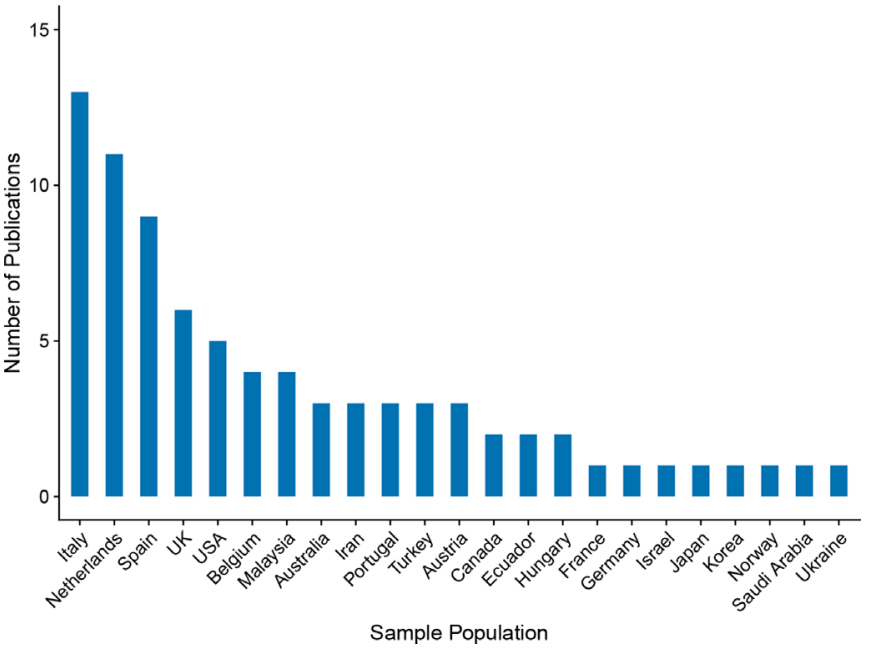

Figure 2 Number of publications by country.

Probo, Robovie, MOnarCH and Paro. Some robots had 'Full' control (no human operator; n=6), 'Goal-based' control (an operator sets a goal but the robot achieves this on its own; $n=8$ ), 'None' (no control; $n=15$ ) or a combination $(\mathrm{n}=16)$. In some cases, control was 'Unknown' (unspecified; $n=25$ ) or not applicable $(n=2)$. In one case, the intended level of control was full, but was not implemented $(n=1)$. A distinction was made between on-site $(\mathrm{n}=27)$ and off-site $(\mathrm{n}=6)$ control.

\section{Purposes the robots serve}

The purpose of the robots (see table 1) was most notably to act as a companion, provide comfort, reduce anxiety, pain and distress, express empathy and increase motivation and joy. In some cases, the role was to provide entertainment and/or distraction or be a buddy/peer. Generally, companion robots shared an overarching aim of improving quality of life.

A further purpose was to teach and coach. This involved informational tasks, for example, information provision, exercise demonstration and feedback delivery, as well as more social tasks, for example, providing motivation, encouragement and support throughout teaching. Exercise demonstration was commonly used when the target population was cerebral palsy and was intended to improve physical functioning $(n=9)$. Information provision was more commonly used to help children with diabetes and contribute to disease self-management $(n=9)$.

Another broad purpose was a therapy tool or assistant. In some cases, the robot-administered therapy (both physical and cognitive), but in most cases, the robot was used in conjunction with a therapist and therapy tools. The robots were often used to engage the child in sessions, provide encouragement and stimulate play and social interactions. In some cases, the robots measured, monitored and recorded data.

In four publications, the purpose of the robot was telepresence. This involved connecting an unwell child to school, supporting educational and social tasks, and in some cases, providing a physical representation of the child in the classroom.

\section{Effectiveness of the robots}

Outcomes considered

Outcomes most frequently considered were acceptability, perceptions of the robot, user evaluations, implementation, engagement and observations of the child-robot interaction; thus reflecting the early stage of research (see table 2). Some publications explored users' emotions, for example, anxiety, stress, depression, pain and anger, while others considered physical functioning or performance on learning tasks (eg, number of correct diabetes quiz questions). Other specific outcomes included adherence to a nutritional diary, subjective assessment by a therapist, level of playfulness, neuropsychological performance, communication behaviours, heart rate, satisfaction and enjoyment, empathy, academic performance, the role of the robot in the interaction and challenges encountered.

\section{Findings and conclusions}

Most publications reported positive outcomes, including generally high acceptance and liking by children, parents, medical staff, teachers and bystanders. However, these results should be treated cautiously given the predominance of subjective and qualitative data (see table 2).

There was only one RCT, ${ }^{14}$ conducted with children who had diabetes, which compared the use of a personal robot, a neutral robot and standard care. Diabetes knowledge significantly improved in both robot groups compared with the control group. The personalised robot group scored higher on self-determination theory determinants, rated the robot as more pleasurable, answered more diabetes quiz questions correctly, were more engaged and were more motivated to play the quiz again, compared with the neutral robot group. This finding that personalisation enhanced the interaction was reflected in other publications. For example, different robots can elicit different roles in the user, ${ }^{15}$ users express different preferences to certain robots ${ }^{1516}$ and different user profiles can be developed to improve child-robot interactions. ${ }^{17}$ The few publications that reported negative findings suggested that the robot did not successfully meet the needs of the children and that better matching was required..$^{18} 19$

Although most publications reported positive outcomes, one study ${ }^{20}$ found the child-robot interaction to be negative, suggesting that the robot encounter was stressful. Changes to the study protocol (eg, introducing the child to the robot in a group context rather than alone) were suggested to resolve this issue.

Some publications explored implementability and technical functioning, identifying challenges including time and assistance required by a therapist, the robot falling over and halting interaction and difficulty with speech interpretation. ${ }^{21-23}$ A predominant conclusion drawn was 


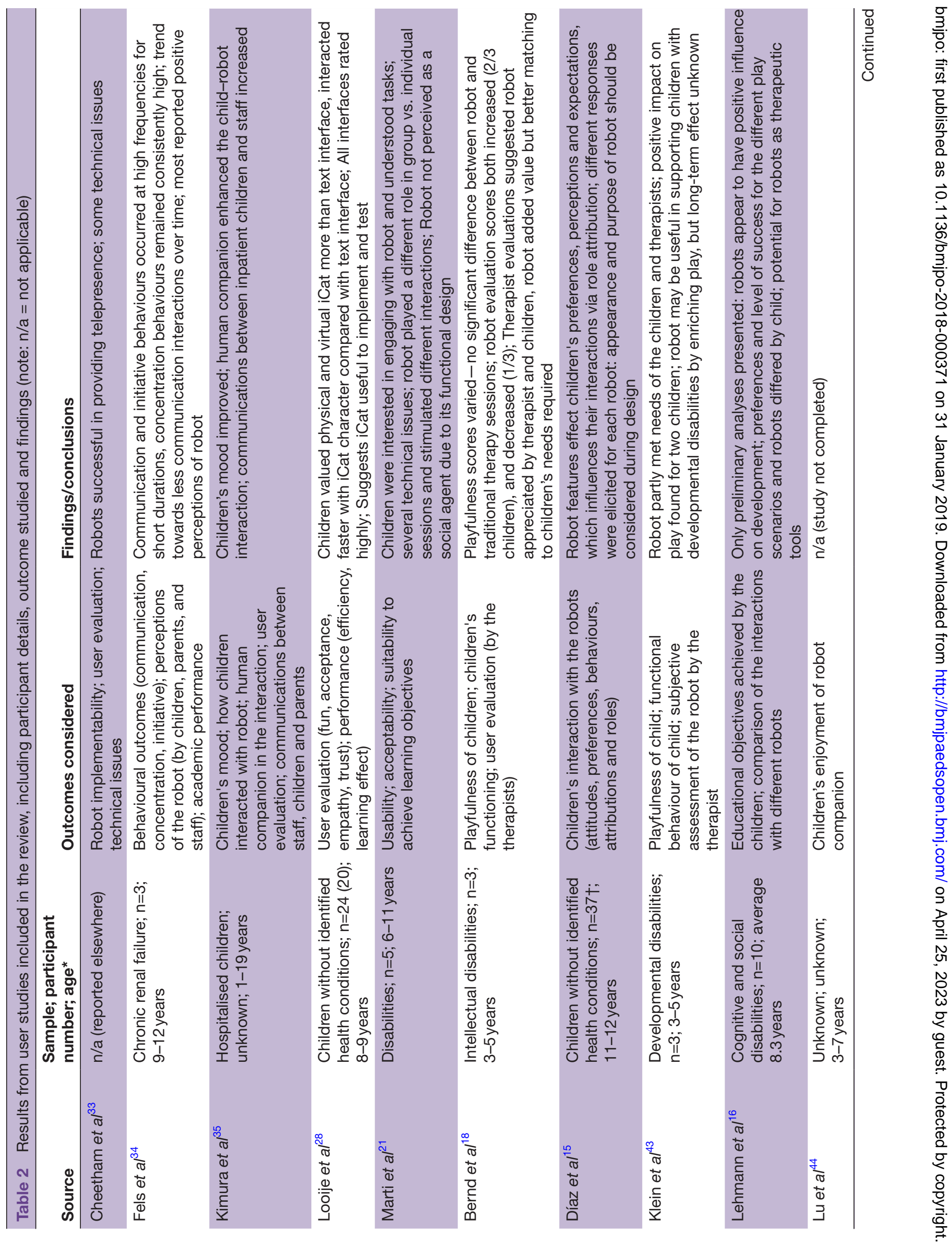




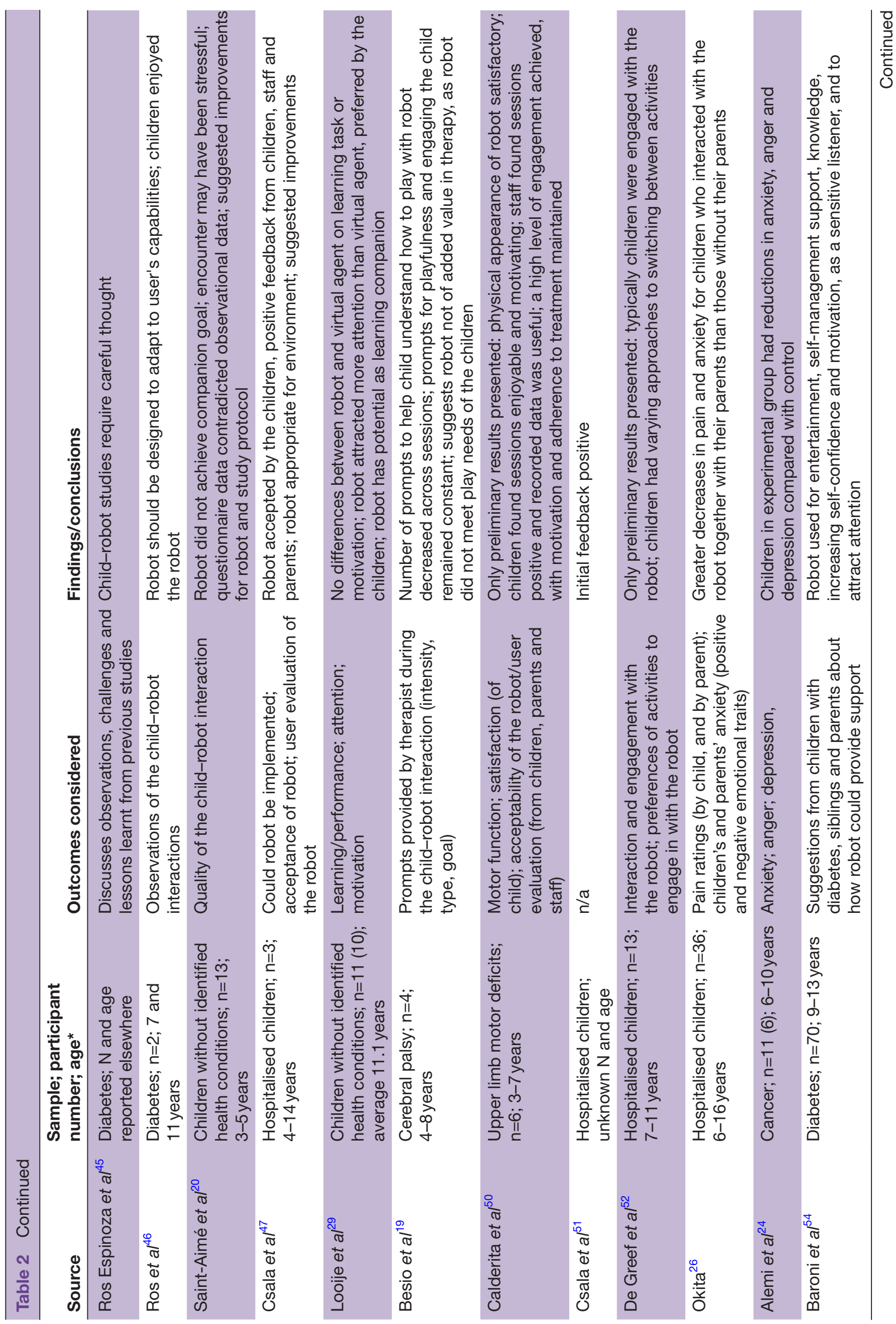

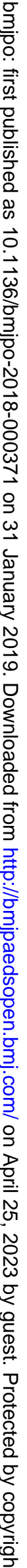




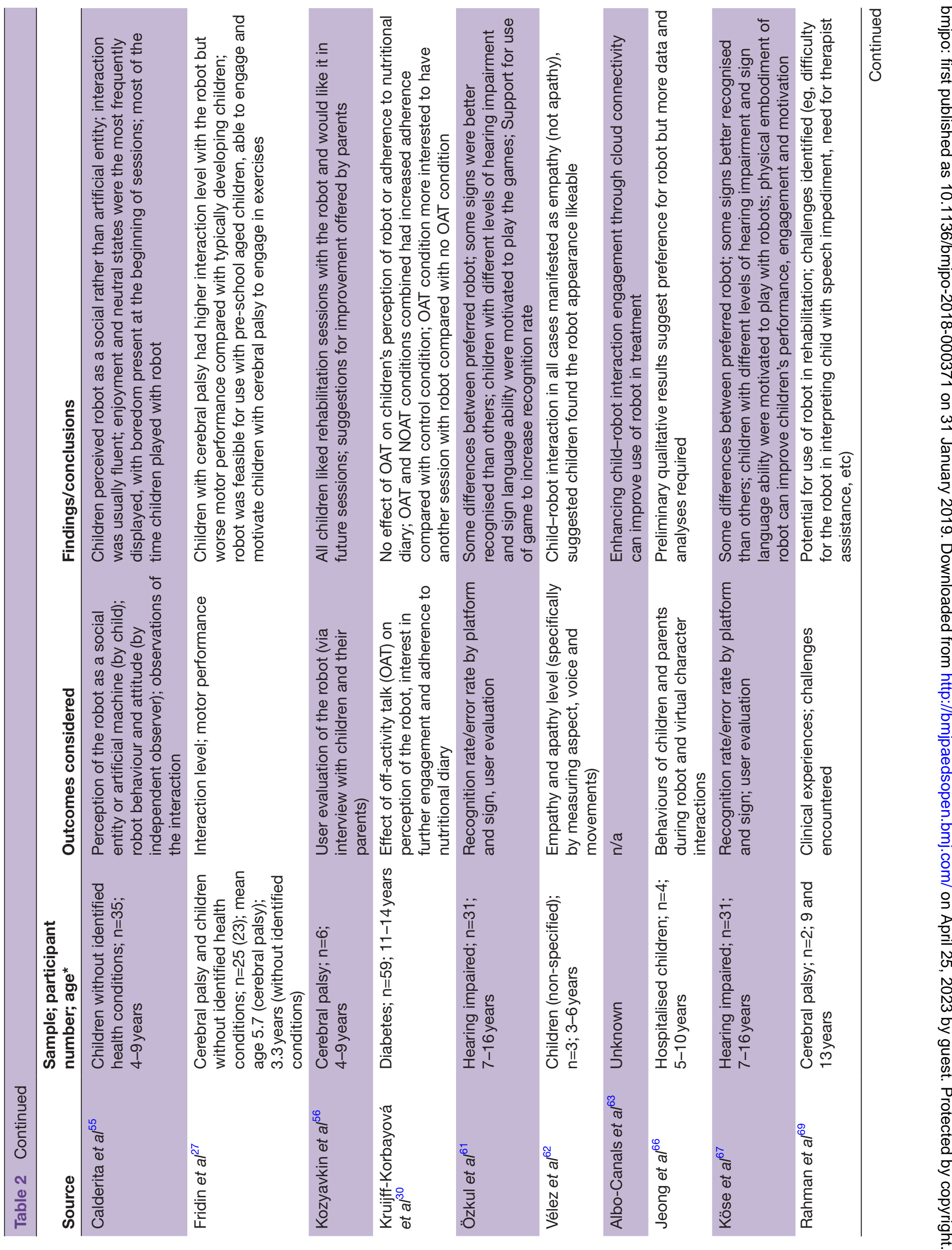




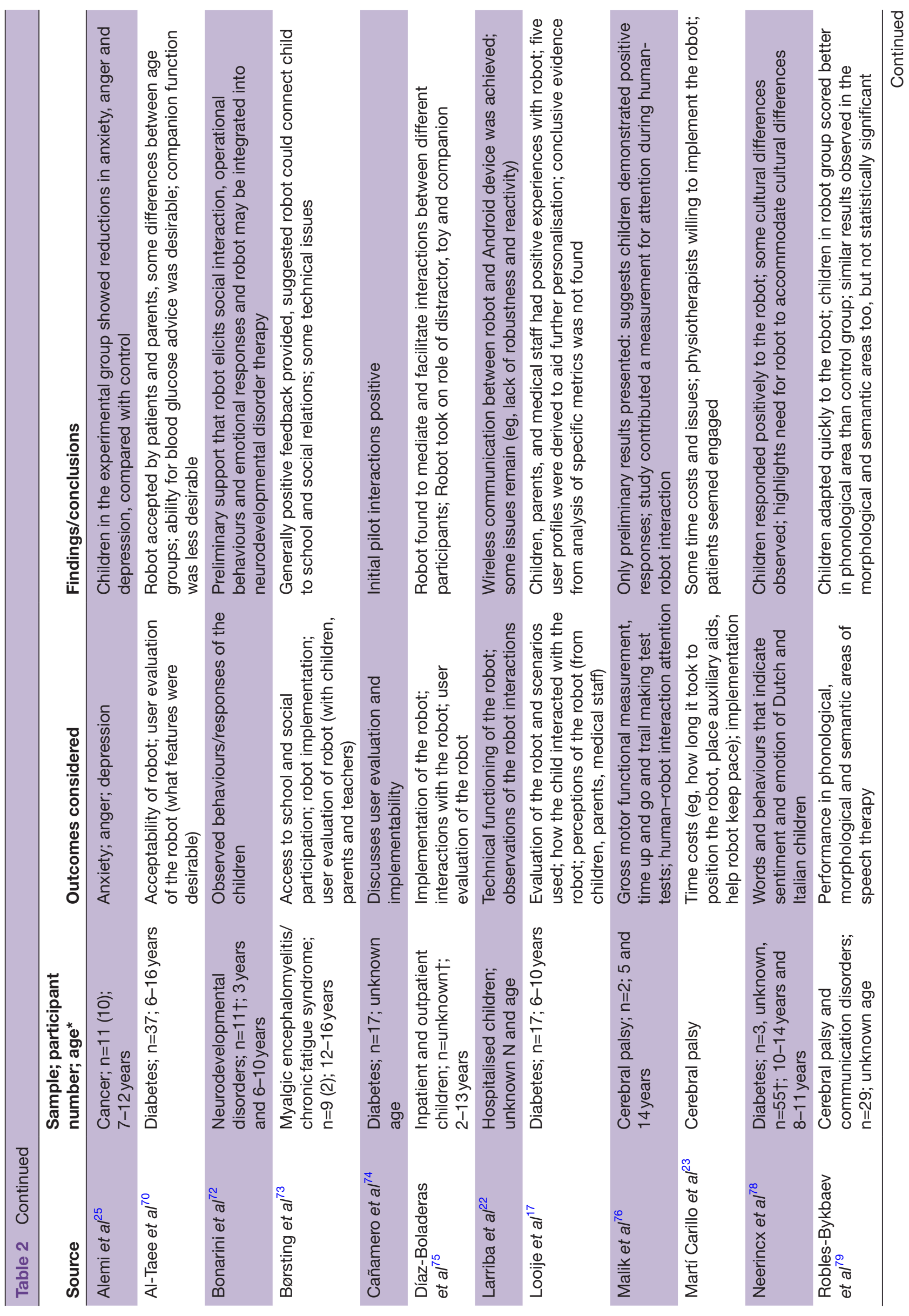

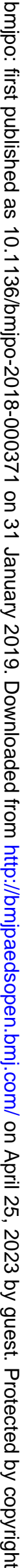




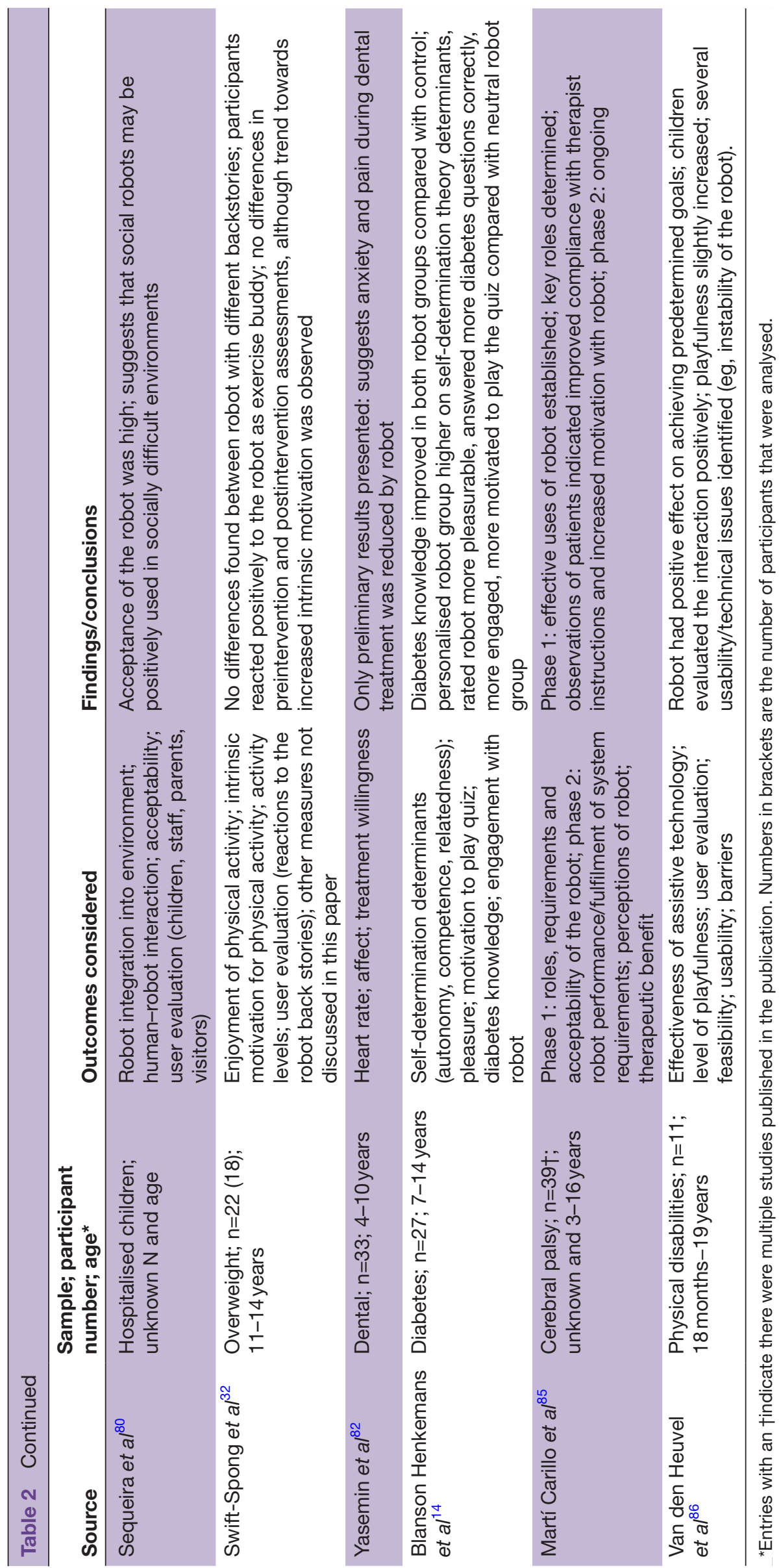




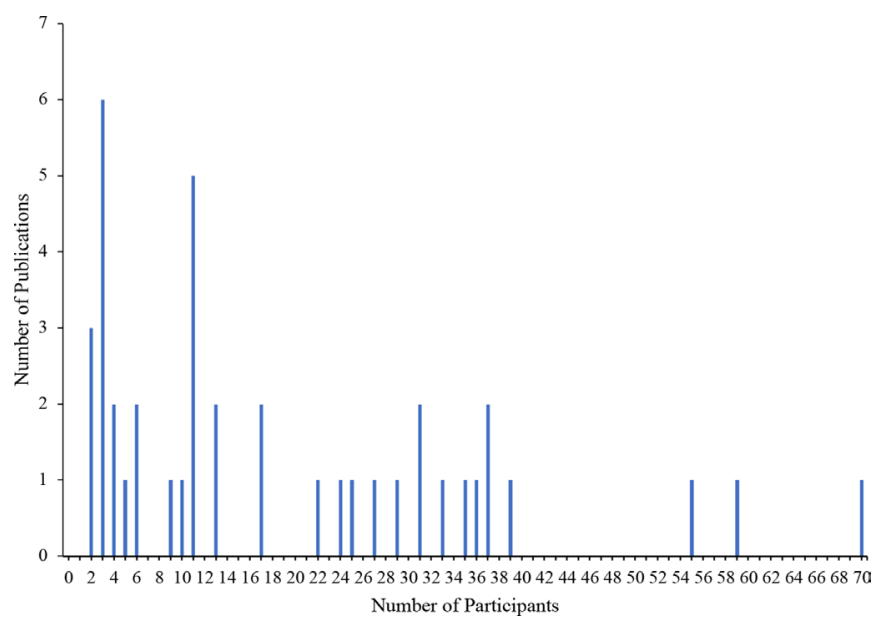

Figure 3 Number of participants in user studies by number of publications.

that further development and testing of the robots was required.

Several studies employed statistical significance testing, and the results are described below. These studies, as well as other non-statistical studies, may help generate more specific hypotheses to be investigated in future controlled study designs, but do not necessarily in and of themselves provide evidence of benefit. One study showed significant reductions in anxiety, anger and depression in patients with cancer in a social robot-assisted therapy group compared with a psychotherapy (control) group. ${ }^{24} 25$ In other work, hospitalised children who interacted with a robot together with their parent demonstrated greater decreases in pain and anxiety compared with those who interacted with the robot alone. ${ }^{26}$ Children with cerebral palsy had a significantly higher interaction level with an exercise demonstration robot (although worse motor performance) than typically developing children, demonstrating the feasibility of the robot for use as a motivating and engaging therapeutic tool. ${ }^{27}$ Children interacted significantly faster with robot characters than with a text interface and significantly valued the robot characters more. ${ }^{28}$ In a related study, children displayed no differences in performance of a learning task or motivation levels when comparing their use of a physical robot or virtual robot, however, the physical robot attracted more attention than the virtual agent and was preferred. ${ }^{29}$ Robot interactions increased adherence to a nutritional diary compared with a no-robot condition among children with diabetes. ${ }^{30}$ An online survey about hypothetical robot therapy for children with disruptive behavioural problems found that while the treatment was considered more acceptable than no treatment, it was less acceptable than internet-based treatment. ${ }^{31}$ Other publications conducted significance testing, but did not find significant effects. ${ }^{18} 32$

\section{How research has developed over time}

The number of publications per year has increased from 2000 to 2017, as shown in figure 4 (note, only part of 2017

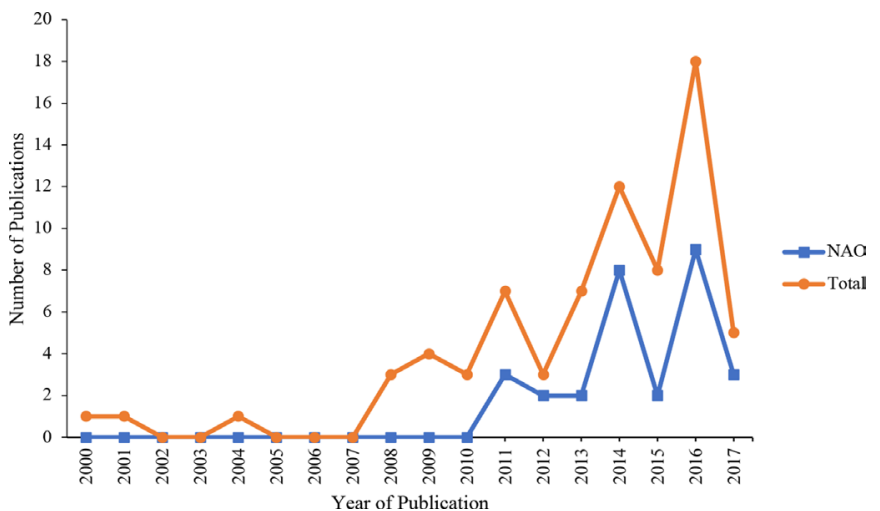

Figure 4 Number of publications by year of publication.

is included in the review). Four experimental studies were published prior to 2014 and seven were published from 2014 onwards; the randomised trial was published in 2017. This suggests that more robust research methods have been employed over time.

\section{DISCUSSION}

\section{Summary of evidence}

This review identified 73 studies that explored the use of social robots for children in healthcare applications. Robots were used to serve a range of purposes, including a companion role, teacher/coach, to connect unwell children to school and to assist in therapeutic and educational endeavours. The wide range of target populations highlights many potential applications, in particular for children with disabilities, impairments, and diabetes, who require intensive ongoing care. Although hospitalisation is not necessarily long term, anxiety, pain and distress are often heightened during hospitalisation. There are potential benefits of using social robots if they can help reduce burden in all three of these contexts. Some of the key findings suggest that social robots can help children with diabetes to improve knowledge; reduce anxiety, anger and depression in children with cancer, and engage children with cerebral palsy in exercises to help improve physical functioning.

The humanoid NAO robot was the most widely used, likely due to its commercial availability, ability to be personalised and relatively autonomous capabilities. Its size and appearance makes it appropriate and appealing. The level of control of robots ranged from almost fully autonomous, to entirely controlled by a human operator. There is a clear need for technological developments to increase the autonomy of all of the robots, particularly in speech recognition and speech production.

\section{Limitations}

While the publications provide support for the use of social robots to help children in healthcare, the quality of the evidence is low, which represents a significant limitation. Specifically, the lack of RCTs and the minimal number of experimental designs hinder the formation of firm conclusions about efficacy and effectiveness. It 
is difficult to determine whether the positive outcomes observed are due to the actions of the robot or some other extraneous variables. For example, the novelty effect of robots must be considered as well as additional attention from researchers or therapists. With longer-term use of robots and increased exposure and integration of robots into society, it is unclear whether the benefits proposed from these early studies will continue, as children may no longer be as easily engaged, motivated, distracted and entertained by this technology.

At the review methodology level, a limitation is that the reference lists of publications were not checked to identify other relevant studies. In addition, papers were limited to the English language, which may have resulted in some missed publications. Formal quality assessment of studies was not performed because scoping studies do not typically aim to assess quality of evidence.

\section{Gaps in the research}

A number of gaps exist in research to date. First, more robust methods need to be employed including experiments and randomised trials with larger sample sizes. Second, the effects of humans on the child-robot interaction requires further RCT exploration. Most of the publications did not explicitly comment on the role of humans in facilitating the child-robot interaction, but of those that did, it appears that humans play a key role in influencing the success and outcomes of the interaction. Third, cultural aspects could be considered, as the majority of research has been conducted in Europe, the UK and the USA. The research paradigm is largely from the perspective of human-robot interaction, with the aim to develop and test robots using small feasibility studies, with subjective reports of acceptability the most common outcome. Research is moving towards experimental designs and more robust health outcomes must be included. Future research will benefit from integrating a stronger healthcare perspective.

\section{Implications for practice}

At present, robots should be considered as adjunctive, rather than as replacements for human care roles. To date, there is insufficient evidence for further practice recommendations to be made.

\section{CONCLUSION}

The results highlight the significant promise and potential held by social robots to help children in healthcare, but demonstrate the need for more and higher quality research. In particular, more RCTs, experimental designs and longer-terms studies are required, with larger sample sizes. There is considerable excitement surrounding the use of robotics in healthcare, but there remains a long way to go in terms of technological developments, integration into the healthcare system and establishment of effectiveness.
Contributors JD made substantial contributions to the acquisition and analysis of data and drafting the work. CS and EB made substantial contributions to the conception of the review, acquisition of funding and revision of the work. $A B$ contributed to the acquisition and analysis of data and revision of the work. All authors approved the final manuscript and agree to be accountable for all aspects of the work

Funding This review was funded by the CARES Seed Grant, University of Auckland.

Competing interests None declared.

Patient consent for publication Not required.

Provenance and peer review Not commissioned; externally peer reviewed.

Open access This is an open access article distributed in accordance with the Creative Commons Attribution Non Commercial (CC BY-NC 4.0) license, which permits others to distribute, remix, adapt, build upon this work non-commercially, and license their derivative works on different terms, provided the original work is properly cited, appropriate credit is given, any changes made indicated, and the use is non-commercial. See: http://creativecommons.org/licenses/by-nc/4.0/.

\section{REFERENCES}

1. Breazeal C. Social robots for health applications. Paper presented at: 33rd Annual International Conference of the IEEE Engineering in Medicine and Biology Society (EMBC 2011); August 30-September 3, Boston, MA, 2011.

2. Dahl T, Boulos M. Robots in health and social care: a complementary technology to home care and telehealthcare? Robotics 2013;3:1-21.

3. Oborn E, Barrett M, Darzi A. Robots and service innovation in health care. J Health Serv Res Policy 2011;16:46-50.

4. Mann JA, MacDonald BA, Kuo I-H, et al. People respond better to robots than computer tablets delivering healthcare instructions. Comput Human Behav 2015;43:112-7.

5. Kuo AA, Etzel RA, Chilton LA, et al. Primary care pediatrics and public health: meeting the needs of today's children. Am J Public Health 2012;102:e17-23.

6. Bemelmans R, Gelderblom GJ, Jonker P, et al. Socially assistive robots in elderly care: a systematic review into effects and effectiveness. J Am Med Dir Assoc 2012;13:114-20.

7. Mordoch E, Osterreicher A, Guse L, et al. Use of social commitment robots in the care of elderly people with dementia: a literature review. Maturitas 2013;74:14-20.

8. Robinson $\mathrm{H}$, MacDonald B, Broadbent $\mathrm{E}$. The role of healthcare robots for older people at home: a review. Int J Soc Robot 2014;6:575-91.

9. Abdi J, Al-Hindawi A, $\mathrm{Ng} \mathrm{T}$, et al. Scoping review on the use of socially assistive robot technology in elderly care. BMJ Open 2018;8:e018815.

10. Sharkey A, Sharkey N. Children, the elderly, and interactive robots. IEEE Robotics \& Automation Magazine. . New York: IEEE, 2011:18. 32-8.

11. Peters MD, Godfrey CM, Khalil H, et al. Guidance for conducting systematic scoping reviews. Int J Evid Based Healthc 2015;13:141-6.

12. Cabibihan $\mathrm{JJ}$, Javed $\mathrm{H}$, Ang $\mathrm{M}$, et al. Why Robots? A survey on the roles and benefits of social robots in the therapy of children with autism. Int J Soc Robot 2013;5:593-618.

13. Pennisi P, Tonacci A, Tartarisco G, et al. Autism and social robotics: a systematic review. Autism Res 2016;9:165-83.

14. Henkemans OAB, Bierman BPB, Janssen J, et al. Design and evaluation of a personal robot playing a self-management education game with children with diabetes type 1. Int J Hum Comput Stud 2017:106:63-76.

15. Díaz M, Nuño N, Saez-Pons J, et al. Building up child-robot relationship for therapeutic purposes: from initial attraction towards long-term social engagement. Paper presented at: IEEE International Conference on Automatic Face \& Gesture Recognition and Workshops (FG 2011); March 21-25, Santa Barbara, CA, 2011.

16. Lehmann $\mathrm{H}$, lacono I, Robins $\mathrm{B}$, et al. 'Make it move': playing cause and effect games with a robot companion for children with cognitive disabilities. Paper presented at: 29th Annual European Conference on Cognitive Ergonomics (ECCE 2011); August 24-26, Rostock, Germany, 2011.

17. Looije R, Neerincx MA, Peters JK, et al. Integrating robot support functions into varied activities at returning hospital visits: supporting child's self-management of diabetes. Int J Soc Robot 2016;8:483-97. 
18. Bernd T, Gelderblom GJ, Vanstipelen S, et al. Short term effect evaluation of IROMEC involved therapy for children with intellectual disabilities. Paper presented at: Second International Conference on Social Robotics (ICSR 2010); November 23-24, Singapore, 2010.

19. Besio S, Carnesecchi M, Converti RM. Prompt-fading strategies in robot mediated play sessions. Paper presented at: 12th European Conference of the Association for the Advancement of Assistive Technology in Europe (AAATE 2013); September 19-22, Algarve, Portugal, 2013.

20. Saint-Aimé S, Grandgeorge M, Le-Pevedic B, et al. Evaluation of Emi interaction with non-disabled children in nursery school using wizard of $\mathrm{Oz}$ technique. Paper presented at: IEEE International Conference on Robotics and Biomimetics (IEEE-ROBIO 2011); December 7-11, Karon Beach, Thailand, 2011.

21. Marti P, Giusti L, Rullo A. Robots as social mediators: field trials with children with special needs. Paper presented at: 10 th Conference of the Association for the Advancement of Assistive Technologies in Europe (AAATE 2009); August 31-September 2, Florence, Italy, 2009.

22. Larriba F, Raya C, Angulo C, et al. Externalising moods and psychological states in a cloud based system to enhance a petrobot and child's interaction. Biomed Eng Online 2016;15(S1):S72.

23. Martí Carrillo F, Butchart J, Knight S, et al. "Help me help you": a human-assisted social robot in paediatric rehabilitation. Paper presented at: 28th Australian Conference on Computer-Human Interaction (OzCHI 2016); November 29-December 2, Tasmania, Australia, 2016.

24. Alemi M, Meghdari A, Ghanbarzadeh A, et al. Effect of utilizing a humanoid robot as a therapy-assistant in reducing anger, anxiety, and depression. Paper presented at: Second RSI/ISM International Conference on Robotics and Mechatronics (ICROM 2014); October 15-17, Tehran, Iran, 2014.

25. Alemi M, Ghanbarzadeh A, Meghdari A, et al. Clinical application of a humanoid robot in pediatric cancer interventions. Int J Soc Robot 2016;8:743-59.

26. Okita SY. Self-other's perspective taking: the use of therapeutic robot companions as social agents for reducing pain and anxiety in pediatric patients. Cyberpsychol Behav Soc Netw 2013;16:436-41.

27. Fridin M, Belokopytov M. Robotics Agent Coacher for CP motor Function (RAC CP Fun). Robotica 2014;32:1265-79.

28. Looije R, Neerincx MA, Lange de V. Children's responses and opinion on three bots that motivate, educate and play. J Phys Agents 2008;2:13-20.

29. Looije R, van der Zalm A, Neerincx MA, et al. Help, I need some body: the effect of embodiment on playful learning. Paper presented at: 21st IEEE International Symposium on Robot and Human Interactive Communication (2012 RO-MAN); September 9-13, Paris, France, 2012.

30. Kruijff-Korbayová I, Oleari E, Baroni I, et al. Effects of off-activity talk in human-robot interaction with diabetic children. Paper presented at: 23rd IEEE International Symposium on Robot and Human Interactive Communication (RO-MAN 2014); August 25-29, Edinburgh, UK, 2014

31. Rabbitt SM, Kazdin AE, Hong JH. Acceptability of robot-assisted therapy for disruptive behavior problems in children. Arch Sci Psychol 2015;3:101-10.

32. Swift-Spong K, Ckf W, Spruijt-Metz D, et al. Comparing backstories of a socially assistive robot exercise buddy for adolescent youth. Paper presented at: 25th IEEE International Symposium on Robot and Human Interactive Communication (RO-MAN 2016); August 2631, New York, NY, 2016

33. Cheetham A, Young C, Fels DI. Interface development for a child's video conferencing robot. Paper presented at: IEA 2000 / HFES 2000 Congress; July 29-August 4, San Diego, CA, 2000.

34. Fels DI, Waalen JK, Zhai S, et al. Telepresence under exceptiona circumstances: enriching the connection to school for sick children. Paper presented at: IFIP TC13 International Conference on HumanComputer Interaction (INTERACT 2001); July 9-13, Tokyo, Japan, 2001.

35. Kimura R, Abe N, Matsumura N, et al. Trial of robot assisted activity using robotic pets in children hospital. Paper presented at: SICE Annual Conference (SICE 2004); August 4-6, Sapporo, Japan, 2004.

36. Goris K, Saldien J, Vanderborght B, et al. The huggable robot Probo: design of the robotic head. Paper presented at: AISB 2008 Convention; April 1-4, Aberdeen, Scotland, 2008.

37. Saldien J, Goris K, Vanderborght B, et al. On the design of an emotional interface for the huggable robot Probo. Paper presented at: AISB 2008 Convention; April 1-4, Aberdeen, Scotland, 2008.

38. Goris K, Saldien J, Lefeber D. Probo, a testbed for human robot interaction. Paper presented at: Fourth ACM/IEEE International Conference on Human-Robot Interaction (HRI 2009); March 11-13, La Jolla, CA, 2009.
39. Marti P, Giusti L, Pollini A. Exploring play styles with a robot companion. Paper presented at: 18th IEEE International Symposium on Robot and Human Interactive Communication (RO-MAN 2009); September 27-October 2, Toyama, Japan, 2009.

40. Marti P, Moderini C, Giusti L, et al. A robotic toy for children with special needs: from requirements to design. Paper presented at: IEEE 11th International Conference on Rehabilitation Robotics (ICORR 2009); June 23-26, Kyoto, Japan, 2009.

41. Böhm P, Gruber T. A novel HAZOP study approach in the RAMS analysis of a therapeutic robot for disabled children. Paper presented at: 29th International Conference on Computer Safety, Reliability and Security (SAFECOMP 2010); September 14-17, Vienna, Austria, 2010.

42. Saldien J, Vanderborght B, Lefeber D. The social robotplatform Probo. Paper presented at: 28th Annual European Conference on Cognitive Ergonomics (ECCE 2010); August 25-27, Delft, Netherlands, 2010.

43. Klein T, Gelderblom GJ, de Witte L, et al. Evaluation of short term effects of the IROMEC robotic toy for children with developmental disabilities. Paper presented at: IEEE 12th International Conference on Rehabilitation Robotics (ICORR 2011), June 29-July 1Zurich, Switzerland, 2011.

44. S-c L, Blackwell N DEY-L. mediRobbi: An interactive companion for pediatric patients during hospital visit. Paper presented at: 14th International Conference on Human-Computer Interaction $(\mathrm{HCl}$ International 2011); July 9-11, Orlando, FL, 2011.

45. Ros Espinoza R, Nalin M, Wood R, et al. Child-robot interaction in the wild: advice to the aspiring experimenter. Paper presented at: 13th International Conference on Multimodal Interaction (ICMI 2011); November 14-18, Alicante, Spain, 2011.

46. Ros R, Demiris Y, Baroni I, et al. Adapting robot behavior to user's capabilities: a dance instruction study. Paper presented at: Sixth ACM/IEEE International Conference on Human-Robot Interaction (HRI 2011); March 6-9, Lausanne, Switzerland, 2011.

47. Csala E, Németh G, Zainkó C. Application of the NAO humanoid robot in the treatment of marrow-transplanted children. Paper presented at: 2012 IEEE 3rd International Conference on Cognitive Infocommunications (CogInfoCom); December 2-5, Kosice, Slovakia, 2012.

48. Nalin M, Baroni I, Sanna A, et al. Robotic companion for diabetic children: emotional and educational support to diabetic children, through an interactive robot. Paper presented at: 11th International Conference on Interaction Design and Children (IDC 2012); June 1215, Bremen, Germany, 2012.

49. Barco A, Albo-Canals J, Mk N, et al. A robotic therapy for children with TBI. Paper presented at: Eighth ACM/IEEE International Conference on Human-Robot Interaction (HRI 2013); March 3-6, Tokyo, Japan, 2013

50. Calderita LV, Bustos P, Suárez Mejías C, et al. Rehabilitation for children while playing with a robotic assistant in a serious game. Paper presented at: International Congress on Neurotechnology, Electronics, and Informatics (Neurotechnix 2013); September 18-20, Algarve, Portugal, 2013

51. Csala E, Németh G, Zainkó C. Application of the NAO humanoid robot in the treatment of bone marrow-transplanted children (demo). Paper presented at: 14th Annual Conference of the International Speech Communication Association (INTERSPEECH 2013); August 25-29, Lyon, France, 2013.

52. De Greeff J, Janssen J, Looije R, et al. Activity switching in childrobot interaction: a hospital case study. Paper presented at: 5th International Conference on Social Robotics (ICSR); October 27-29, Bristol, UK, 2013.

53. Ryu GJ, Kang JB, Kim CG, et al. Development of a robot remote support system for student with health impairment. Paper presented at: Seventh International Convention on Rehabilitation Engineering and Assistive Technology (i-CREATe 2013), August 29-31Gyeonggido, South Korea, 2013.

54. Baroni I, Nalin M, Baxter P, et al. What a robotic companion could do for a diabetic child. Paper presented at: 23rd IEEE International Symposium on Robot and Human Interactive Communication (ROMAN 2014); August 25-29, Edinburgh, UK, 2014.

55. Calderita LV, Manso LJ, Bustos P, et al. THERAPIST: towards an autonomous socially interactive robot for motor and neurorehabilitation therapies for children. JMIR Rehabil Assist Technol 2014:1:1-25.

56. Kozyavkin V, Kachmar O, Ablikova I. Humanoid social robots in the rehabilitation of children with cerebral palsy. Paper presented at: Eighth International Conference on Pervasive Computing Technologies for Healthcare (PervasiveHealth 2014); May 20-23, Oldenberg, Germany, 2014. 
57. Lewis $M$, Cañamero L. An affective autonomous robot toddler to support the development of self-efficacy in diabetic children. Paper presented at: 23rd IEEE International Symposium on Robot and Human Interactive Communication (RO-MAN 2014); August 25-29, Edinburgh, UK, 2014

58. Malik NA, Yussof H, Hanapiah FA. Development of imitation learning through physical therapy using a humanoid robot. Paper presented at: International Conference on Robot PRIDE 20132014 - Medical and Rehabilitation Robotics and Instrumentation (ConfPRIDE 2013-2014); June 21-22, Selangor, Malaysia, 2014.:191-7

59. Malik NA, Yussof H, Hanapiah FA, et al. Human Robot Interaction (HRI) between a humanoid robot and children with cerebral palsy: experimental framework and measure of engagement. Paper presented at: 2014 IEEE Conference on Biomedical Engineering and Sciences (IECBES); December 8-10, Miri, Malaysia, 2014.

60. Messias J, Ventura R, Lima P, et al. A robotic platform for edutainment activities in a pediatric hospital. Paper presented at: 2014 IEEE International Conference on Autonomous Robot Systems and Competitions (ICARSC); May 14-15, Espinho, Portugal, 2014.

61. Özkul A, Köse H, Yorganci R, et al. Paper presented at: IEEE International Conference on Robotics and Biomimetics (IEEE-ROBIO 2014). Robostar: an interaction game with humanoid robots for learning sign language; December 5-10, Bali, Indonesia, 2014.

62. Vélez P, Gallegos K, Silva J, et al. ROBSNA: Social robot for interaction and learning therapies. Paper presented at: 14th Annual Conference on Towards Autonomous Robotic Systems (TAROS 2013); August 28-30, Oxford, UK, 2014.

63. Albo-Canals J, Fernández-Baena A, Boldu R, et al. Enhancing long-term children to robot interaction engagement through cloud connectivity. Paper presented at: 10th Annual ACM/IEEE International Conference on Human-Robot Interaction (HRI 2015); March 2-5, Portland, OR, 2015

64. Alotaibi M, Choudhury I. A social robotics children diabetes management and educational system for Saudi Arabia: system architecture. Paper presented at: 2015 Second International Conference on Computer Science, Computer Engineering, and Social Media (CSCESM); Lodz, Poland, September 21-23, 2015.

65. Gonçalves D, Arsenio A. Human-driven multi-robot design process for social interactions with children on complex environments. Paper presented at: Sixth International Conference on Automation, Robotics and Applications (ICARA 2015); February 17-19, Queenstown, New Zealand, 2015.

66. Jeong S, Logan DE, Goodwin MS, et al. A social robot to mitigate stress, anxiety, and pain in hospital pediatric care. Paper presented at: 10th ACM/IEEE International Conference on Human-Robot Interaction (HRI 2015); March 2-5, Portland, OR, 2015.

67. Köse H, Uluer P, Akalın N, et al. The effect of embodiment in sign language tutoring with assistive humanoid robots. Int $J$ Soc Robot 2015;7:537-48.

68. McCarthy C, Butchart J, George M, et al. Robots in rehab: towards socially assistive robots for paediatric rehabilitation. Paper presented at: 27th Australian Conference on Human-Computer Interaction (OzCHI 2015); December 7-10, Melbourne, Australia, 2015.

69. Rahman RAA, Hanapiah FA, Basri HH, et al. Use of humanoid robot in children with cerebral palsy: the ups and downs in clinical experience. Procedia Comput Sci 2015;76:394-9.

70. Al-Taee MA, Kapoor R, Garrett C, et al. Acceptability of Robot Assistant in Management of Type 1 Diabetes in Children. Diabetes Technol Ther 2016;18:551-4.

71. Arnold L. Emobie: a robot companion for children with anxiety. Paper presented at: 11th ACM/IEEE International Conference on Human-Robot Interaction (HRI 2016); March 7-10, Christchurch, New Zealand, 2016.
72. Bonarini A, Clasadonte F, Garzotto F, et al. Playful interaction with Teo, a mobile robot for children with neurodevelopmental disorders. Paper presented at: Seventh International Conference on Software Development and Technologies for Enhancing Accessibility and Fighting Info-exclusion (DSAl 2016); December 1-3, Vila Real, Portugal, 2016.

73. Børsting J, Culén AL. A robot-avatar: easier access to education and reduction in isolation? Paper presented at: Eighth International Conference on e-Health (MCCSIS 2016); July 1-3, Funchal, Portugal, 2016.

74. Cañamero L, Lewis M. Making new "New Al" friends: designing a social robot for diabetic children from an embodied Al perspective. Int J Soc Robot 2016;8:523-37.

75. Díaz-Boladeras $M$, Angulo $C$, Domènech $M$, et al. Assessing pediatrics patients' psychological states from biomedical signals in a cloud of social robots. Paper presented at: XIV Mediterranean Conference on Medical and Biological Engineering and Computing (MEDICON 2016); March 31-April 2, Paphos, Cyprus, 2016.

76. Malik NA, Yussof $H$, Hanapiah FA. Potential use of social assistive robot based rehabilitation for children with cerebral palsy. Paper presented at: 2016 Second IEEE International Symposium on Robotics and Manufacturing Automation (ROMA); September 25-27, Ipoh, Malaysia, 2016.

77. Meghdari A, Alemi M, Khamooshi M, et al. Conceptual design of a social robot for pediatric hospitals. Paper presented at: Fourth International Conference on Robotics and Mechatronics (ICRoM 2016); October 26-28, Tehran, Iran, 2016.

78. Neerincx A, Kaptein R, Oleari E, et al. Child's culture-related experiences with a social robot at diabetes camps. Paper presented at: 11th ACM/IEEE International Conference on Human-Robot Interaction (HRI 2016); March 7-10, Christchurch, New Zealand, 2016.

79. Robles-Bykbaev V, Ochoa-Guaraca M, Carpio-Moreta M, et al. Robotic assistant for support in speech therapy for children with cerebral palsy. Paper presented at: IEEE International Autumn Meeting on Power, Electronics and Computing (ROPEC 2016); November 9-11, Ixtapa, Mexico, 2016.

80. Sequeira JS, Ferreira IA. Lessons from the MOnarCH project. Paper presented at: 13th International Conference on Informatics in Control, Automation and Robotics (ICINCO 2016); July 29-31, Lisbon, Portugal, 2016.

81. Ullrich D, Diefenbach S, Butz A. Murphy Miserable robot - a companion to support children's wellbeing in emotionally difficult situations. Paper presented at: ACM CHI 2016; May 7-12, San Jose, CA, 2016

82. Yasemin M, Kasımoğlu Y, Kocaaydin S, et al. Management of dental anxiety in children using robots. Paper presented at: Ninth International Conference on Advances in Computer-Human Interactions (ACHI 2016); April 24-28, Venice, Italy, 2016.

83. Blanson Henkemans OA, Van der Pal S, Werner I, et al. Learning with Charlie: a robot buddy for children with diabetes. Paper presented at: ACM/IEEE International Conference on Human-Robot Interaction (HRI 2017); March 6-9, Vienna Austria, 2017.

84. Gelsomini M, Leonardi G, Degiorgi M, et al. Puffy - an inflatable mobile interactive companion for children with Neurodevelopmental Disorders. Paper presented at: ACM CHI 2017; May 6-11, Denver, CO, 2017

85. Martí Carrillo F, Butchart J, Knight S, et al. In-situ design and development of a socially assistive robot for paediatric rehabilitation. Paper presented at: ACM/IEEE International Conference on HumanRobot Interaction (HRI 2017); March 6-9, Vienna, Austria, 2017.

86. van den Heuvel RJ, Lexis MA, de Witte LP. Can the IROMEC robot support play in children with severe physical disabilities? A pilot study. Int J Rehabil Res 2017;40:53-9. 